\title{
Agriculture and household nutrition security-development practice and research needs
}

\author{
John McDermott • Myriam Aït-Ä̈ssa • Julien Morel • \\ Nancy Rapando
}

Received: 2 June 2013 / Accepted: 2 August 2013 / Published online: 30 August 2013

(C) The Author(s) 2013. This article is published with open access at Springerlink.com

\begin{abstract}
Aligning agriculture to improve household nutrition security requires agricultural research and development specialists to understand nutrition objectives and be able to contribute to integrated agriculture-health programs. This paper builds on discussions during the household nutrition security session at the second Global Conference on Agriculture Research for Development (GCARD2). To begin, there is a summary of the variety of ways essential nutrition knowledge can underpin nutrition-sensitive agriculture. Lessons for improving nutrition through agriculture, including: efficient and effective production of diversified, highly nutritious and biofortified foods, enhancing value chains to improve nutritional quality and food safety, and better policies and investments, are highlighted. Frequently missing in discussions on nutrition-sensitive agriculture are the requirements for capacity development and extension - critical requirements to scaling-out and sustaining improved nutrition outcomes through agriculture. Gender, local empowerment and other key issues are discussed, as are the opportunities for cost-effective approaches to be implemented
\end{abstract}

\author{
J. McDermott $(\bowtie)$ \\ International Food Policy Research Institute (IFPRI), 2033 K St NW, \\ Washington, DC 20006, USA \\ e-mail: j.mcdermott@cgiar.org \\ M. Aït-Aïssa $\cdot$ J. Morel \\ Action Contre La Faim, 4 rue Niepce, 75662 Paris Cedex 14, France \\ M. Aït-Aïssa \\ e-mail: maitaissa@actioncontrelafaim.org \\ J. Morel \\ e-mail: morel@actioncontrelafaim.org

\section{N. Rapando} \\ Volunteer Efforts for Development Concerns Uganda, P.O BOX \\ 1244, Kampala, Uganda \\ e-mail: rapandon@vedco.or.ug \\ N. Rapando \\ e-mail: rapsando@yahoo.com
}

and expanded. Finally, research gaps, approaches and priorities to improve practice and anticipate and respond to dynamic changes in biological and social systems are discussed. Four next steps are summarized: (1) align agricultural interventions with those in health services, water and sanitation and social protection; (2) implement approaches to accelerate learning for development implementation and policy and investment enabling; (3) build local and national capacity to adapt and innovate; and (4) empower women and disadvantaged communities, in which the burden and solutions to nutrition security are found.

Keywords Agriculture $\cdot$ Nutrition $\cdot$ Household · Nutrition-sensitive $\cdot$ Food $\cdot$ Multi-sectoral

\section{Introduction}

The agricultural challenge of feeding a growing and more affluent global population in the coming decades is well known. Also well-known is the nutrition challenge of reducing childhood stunting, championed by several international processes including the Scaling Up Nutrition (SUN) movement and the 1,000 days initiative, ${ }^{1}$ which campaign to reduce chronic malnutrition or stunting. Micronutrient malnutrition is also a global priority with an estimated 2 billion people lacking essential micronutrients. There are powerful arguments linking early childhood stunting with cognitive and physical underdevelopment (Maluccio et al. 2005; Grantham-McGregor et al. 2000) and reduced school attendance and performance (Matorell et al. 2010), which translate into reductions of Gross Domestic Product (GDP) from $2 \%$ to $8 \%$ (Gwatkin et al. 2007).

\footnotetext{
${ }^{1}$ The "1,000 days period", refers to the time from the start of a mother's pregnancy until the child is two years old.
} 
Traditionally in public health, improving nutrition has focused on direct nutrition (or nutrition-specific) interventions. Largely, these interventions have proved effective and provided considerable convincing data from randomized trials. Increasingly, governments and donors wish to invest in agriculture, water and sanitation, gender empowerment and social protection to make these areas more nutrition-sensitive in order to accelerate nutritional benefits that otherwise may come more slowly as economic development progresses, and thus avoid the recurring costs of nutrition-specific campaigns and programs. Pragmatically, shorter-term and effective nutrition-specific programs are combined with more indirect nutrition-sensitive investments, depending on the development context.

Agriculture's contribution to feeding people is well documented (Spielman and Pandya-Lorch 2009). Its contribution to nourishing them is less evident (Gillespie et al. 2012; Masset et al. 2011; Webb 2013). At the recent second Global Conference on Agricultural Research for Development (GCARD2), ${ }^{2}$ a session, bringing together practitioners and researchers, was convened to address the challenge of how agriculture can contribute more to improving household nutrition. The session built on current practice and research to consider:

1. How agricultural interventions can be more nutritionsensitive;

2. What, where and how agriculture can be linked to other sectors to improve nutrition; and

3. What strategies and capacities are needed to improve agriculture's contribution to increase household nutrition security.

This paper builds on discussions at GCARD2 (Lynn Brown of WFP was the main organizer and Barbara Burlingame of FAO, the session Chair) from the diverse perspectives of the co-authors, who come from research (McDermott), development (Aït-Aïssa and Morel) and extension (Rapundo) organizations. In this paper, we bring together these diverse perspectives to:

1. Summarize the nutrition knowledge that underpins current practice,

2. Highlight some recent initiatives, case studies and lessons learned in agricultural development for improved nutrition outcomes,

3. Comment on capacity development and extension support, and

4. Identify key research needs to support a more ambitious agricultural agenda for improving nutrition outcomes.

\footnotetext{
${ }^{2}$ Global Conference on Agriculture Research for Development GCARD2), 29 October - 1 November, Punta del Este, Uruguay. Documents from the session on household nutrition security can be found at http://www.egfar.org/ content/p-12-household-nutrition-security and a report of the conference in Food Security 5:129-134: 2013.
}

We have drawn on many of the contributions at the GCARD2 household nutrition security session, but have also included some elements that were not presented.

\section{Current nutrition development theory and practice and links to nutrition-sensitive agriculture}

Undernutrition can be the outcome of insufficient food intake, impaired gut absorption, poor care and feeding of children and a number of other bio-physical and socioeconomic factors. Undernutrition is classified into different types: stunting or chronic undernutrition; wasting or acute undernutrition; underweight; and micronutrient deficiencies. Undernutrition remains one of highest burdens of public health concerns, with 165 million children underfive years of age suffering from stunting and 52 million from wasting in 2011, while more than 2 billion people are deficient in micronutrients, mainly vitamin A, iron, iodine \& zinc (UNICEF-WHO-The World Bank 2012). Progress has been made during the last decade, but much remains to be done, particularly in Africa where progress on reducing undernutrition has been slow, with a few exceptions, and undernutrition remains the largest underlying risk associated with high disease burdens (Lim et al. 2012).

Conceptual frameworks for improving nutrition outcomes have been relatively consistent since 1990, based on an initial framework developed by UNICEF (1990). For example, Fig. 1 shows a modification of this framework used by Action Contre La Faim (ACF). ACF applies the nutrition security definition of the World Bank (2013) as "the ongoing access to the basic elements of good nutrition, i.e. a balanced diet, safe environment, clean water, and adequate health care (preventive and curative) for all people, and the knowledge needed to care for and ensure a healthy and active life for all household members". This implies that nutritional security goes beyond the traditional concept of food security (access, availability, stability and utilization of food) and recognizes that nutritional status is dependent on a wide and multi-sectoral array of factors. Another element of the ACF strategy is to apply a mixed strategy of combinations of treatments of acute malnutrition with targeted direct nutrition interventions for immediate impacts, as well as investing in packages of nutrition-sensitive interventions that address the immediate and underlying multi-sectoral determinants of undernutrition (Ruel and Hoddinott 2008). Based on these key principles, the following operational guidelines are used by ACF in planning its nutrition security programs:

1. Address simultaneously outcomes (treatment) and causes (prevention) of undernutrition, both nutrition-specific and nutrition-sensitive as appropriate 


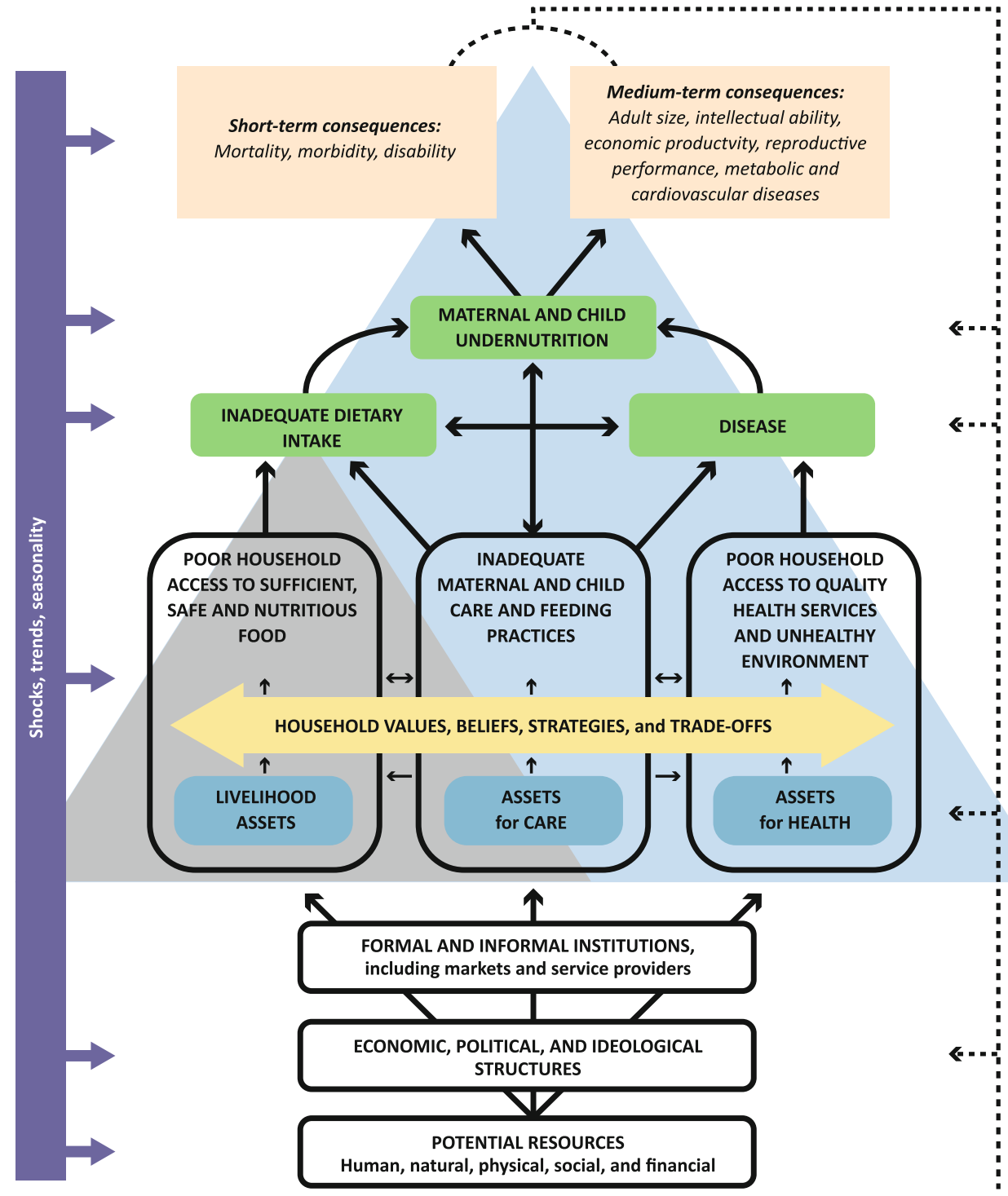

Fig. 1 Conceptual framework of malnutrition adapted from UNICEF 1990 and Black et al. 2008 as used by Action Contre la Faim (ACF), modified from Black et al. 2008 and UNICEF 1990)

2. Work multisectorally: promote coherence and synergies amongst sectors

3. Focus on 1,000 days window and empower women

4. Assess nutritional impacts, both positive and negative (do no harm)

Also presented at the GCARD2 session was the World Bank's strategy and practice for improving nutrition outcomes. Their analysis is that in many countries, despite robust economic and agricultural growth, malnutrition rates remain stubbornly high. While nutrition outcomes improved more in countries with pro-poor nutrition strategies and equitable growth (Webb and Block 2012), these factors were insufficient to improve child nutrition outcomes.
Beyond nutrition-specific interventions, the World Bank is focusing on small nutrition-sensitive adjustments to its large development portfolio across different sectors. Five specific steps were presented:

1. "Explicitly incorporate nutritional considerations into initial design of projects/policies;

2. Integrate nutritional considerations as elements of investments, not necessarily as the primary objective;

3. Modify the design/consider alternatives to minimize unintended negative consequences and maximize positive impacts;

4. Support nutritional objectives with technical capacity within countries; and 
5. Monitor and evaluate nutrition impacts with appropriate indicators." (Tanimichi-Hoberg 2012)

The World Bank, together with other international organizations and governments, has embraced the 1,000 days focus in regions with high malnutrition burdens. Internally and with key partners, it has supported cross-sectoral knowledge and information flows through a platform, Secure Nutrition, convened jointly by the Health, Social Development and Agricultural Sectors. One major achievement of the program is the development of guidance notes for improving nutrition across sectors (World Bank 2013). The guidance notes are intended to help task team leaders of the World Bank, country partners and other development partners to adjust the design of existing and future operations to make them more nutrition sensitive.

In its own agricultural operations, the World Bank, in its 2013-15 agricultural action plan is committed to following the five step process above in its planned \$7-9 billion agricultural investment portfolio.

\section{Current practices and lessons learned in nutrition-sensitive agriculture}

In the GCARD2 household nutrition security session, most presentations were on current nutrition-sensitive agricultural practice and lessons learned. Current good practice in agricultural development revolves around household production of more nutritious foods, such as fruits and vegetables supplemented with milk, egg or meat production. This approach has been developed over several decades (see for example Iannotti et al. 2009). The dominant paradigm in agricultural development is market-oriented smallholder development. This is based on the fact that in countries with a highburden of malnutrition in South Asia and sub-Saharan Africa, smallholder farms dominate and are likely to dominate for the foreseeable future. It is also based on the assumption that smallholders will be market-oriented, and that market incentives will drive increases in the production of food and its quality and safety. Typically, a variety of value chain approaches, from informal to supermarket-oriented, are used. Diversifying the food production options for greater availability and access to highly nutritious foods and enhancing nutrition quality of staple foods, for example through biofortification, to increase levels of micronutrients, are the main strategies for linking agricultural production to improved diet quality.

However, experience has shown that while production of nutritious foods is necessary to improve diet quality for macro- and micro-nutrients, depending on circumstance, it is not sufficient for improving nutrition outcomes such as decreasing stunting. Thus, current good practice combines some type of homestead or smallholder agricultural productivity component with other health and social innovations. These interventions intend to improve nutritious food consumption, income, intra-household equity, and child care. Some examples below illustrate the practice and lessons learned from these more integrated agriculture - nutritionhealth programs.

Health Gardens approach in West Africa: the example of the health gardens implemented in Kita District, Mali, 2007-2010

High rates of stunting and micronutrient deficiencies as well as inappropriate feeding practices identified in West Africa has led ACF to develop "Health and Nutrition Gardens". This program combines the traditional home gardens approach, such as access to inputs, training in crop production, and postharvest practices, with a number of gender empowerment and nutrition education components including:

- Evaluation of food consumption patterns,

- Selection of micronutrient-rich vegetables to complement deficient diets,

- Research for elaboration of improved recipes combining balanced and local food,

- Cooking demonstrations,

- Awareness and nutritional education to improve mother and child feeding practices.

In response to food and nutritional insecurity in Mali, the Health and Nutrition Gardens program was launched in 1,264 households between 2007 and 2010. An important element of the program was to evaluate its impacts, looking at benefits in the program households, in non-program households in program villages and in households in non-program villages. Ten of 36 program villages were randomly sampled and households further subsampled at random. The main results showed increased availability of vegetables during the year from 5 to 9 months and increased production of vegetable crops $(+165 \%)$. Diet diversity among the whole population improved, with average household dietary diversity scores increasing from 5.3 to 6.6 out of 12 , to levels considered diverse under Sahelian conditions. The proportion of young children consuming vitamin A-rich foods increased from $59 \%$ to $99 \%$. A high proportion of beneficiaries $(88 \%)$ demonstrated knowledge of malnutrition versus $68 \%$ in non-beneficiaries. Based on these results, ACF is currently scaling up the Health and Nutrition Gardens approach in West Africa, Latin America, the Caucasus region and Asia. Additional information is still required to identify pathways, beyond increasing more nutritious food consumption and better nutrition knowledge, that can lead to improved nutritional status. 
Enhancing practices of optimal nutrition and care in Myanmar - the SUSTAIN project

ACF, in association with GRET (Groupe de Recherche et d'Echange Technologique) and WHH (Welthungerhilfe), took the opportunity of investigating impact pathways for nutritional status more carefully within a food security program in Myanmar, beginning in 2012. The project started out with a comprehensive baseline survey in order to understand the diversity of wild and indigenous foods, agricultural productivity and nutrition availability, food consumption patterns, dietary intake and micronutrient adequacy, seasonality, nutrition needs of different risk groups, care given to children, intra-household dynamics and gender considerations in five diverse agro-ecological areas of intervention.

A basic impact pathway diagram (Fig. 2) was developed. The baseline information provided additional details of options in a few areas. On agricultural production, locally applicable options for increasing production of nutritious foods were made. In addition, the availability of wild/indigenous foods, particularly in hunger periods was noted. Much greater specificity was also developed around infant and young child feeding and care practices, particularly around local production of complementary foods for infants and young children. Finally, the baseline survey also provided ideas for empowering women with different livelihood and income opportunities. The baseline survey and the impact pathways should provide a stronger conceptual basis for understanding and evaluating nutrition-sensitive options in this context. In the impact pathway thinking, particular attention was paid to assessing risk and reducing the chances of introducing harmful change that would adversely impact women, infants and young children.

Helen Keller International Programs in the Asia-Pacific region

Helen Keller International (HKI) has a long history of work on agriculture-nutrition issues (Iannotti et al. 2009). They highlighted some of their key practices and lessons learned. One area of new practice is building the capacity for learning and institutional actions at national and regional levels that can support a variety of projects. This includes multi-partner collaboration for establishing national nutrition surveillance systems to provide timely data to policymakers and researchers. It also includes the Essential Nutrition Actions (ENA) approach, which brings together relevant contact points in health services with relevant stakeholders in the communities - including

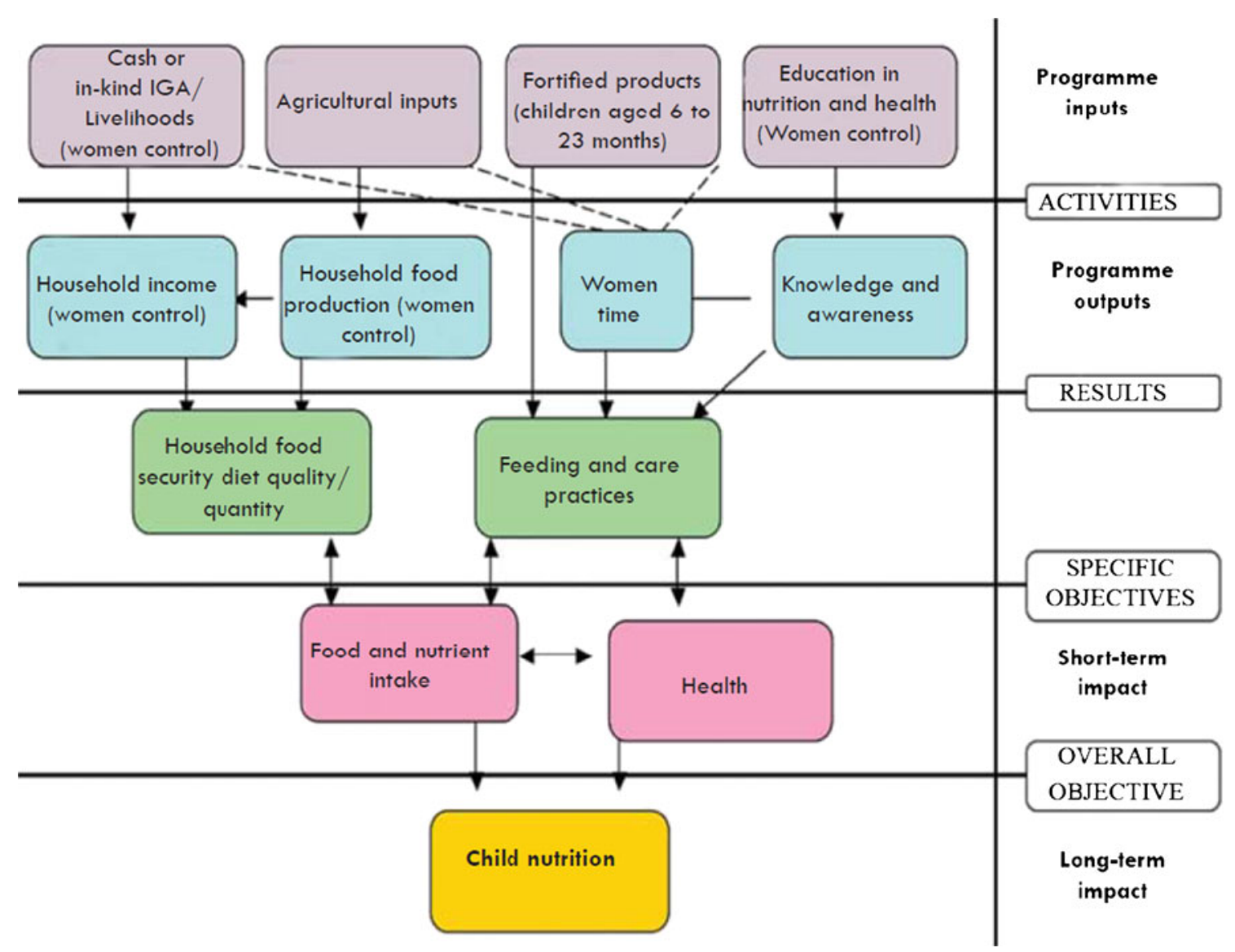

Fig. 2 Pathways through which the intervention is expected to affect nutritional status of children, Myanmar (Northern Rakhine State, Northern Shan State, Ayeyarwaddy Region, Sagaing Division, Yangon Division) - 2012-2014 
farmers' groups and extension services - with consistent nutrition information and doable actions in seven nutrition action areas. Household nutrition issues of focus are diet diversity, antenatal care, maternal nutrition and infant and young child feeding (IYCF) practices. Household nutrition can be enhanced with complementary interventions such as micronutrient supplementation (sprinkles, vitamin A supplementation), biofortification of crops (through conventional and transgenic breeding), training and counselling on optimal maternal nutrition and infant/young child feeding practices and dietary diversification through agriculture. Attention to inequality, both gender (assets, time poverty, market exclusion, and others) and marginalized groups including landless and low-caste farmers, is seen as an essential step in reducing stunting.

One important lesson from HKI's experiences is that the objectives of households have changed and focusing on agricultural production of nutritious foods must consider both market-oriented income opportunities as well as household consumption. A broad area of skills and income opportunities has been pursued, including post-harvest processing and business skills; creating non-farm nutrition-related jobs (poultry shed construction, vaccination) and technologies for the landless and land-constrained. Further investment is recommended, in particular on retaining nutrition content in postharvest processing and marketing nutrition-rich convenience foods. The second important lesson is in looking at intrahousehold equity issues and gender empowerment. Women's time poverty and the relative power and sharing of roles and decision making between men and women are critical in reducing exclusive breast feeding and improving household nutrition security. A third important lesson is the importance of building in monitoring and evaluation in order to enhance learning. This has included actions ranging from better data on food production and consumption to randomized trials in Cambodia to test nutrition outcomes of foodbased approaches.

Clearly, much has been learned about programs that integrate agriculture, nutrition and health as described by ACF and HKI. Over the next several years, additional evidence should provide additional information on improving impact and increasing the reach of these programs. Beyond such programs, another key area explored was how more standard smallholder agricultural production and agricultural systems interventions can improve nutrition through improving the availability, access, utilization and sustainability of more nutritious and diverse foods, leading to improved diet quality. There were two key pathways for improving access discussed. The first is through increasing incomes of farmers, laborers and market agents to be able to purchase foods as well as other goods and services. The second is the importance of increasing agricultural productivity and efficiency on reducing food prices, particularly for staple grains since the mid-1970. Lower staple prices, allows households to purchase, more nutritious and expensive foods such as milk, eggs, meats and pulses with their food budgets. A recent review (Wiggins and Keats 2013) describes in more detail analysis of productivity, income and price effects over the past decades.

\section{Biofortification}

A large part of the population that is micronutrient deficient, particularly in Asia and Africa, live in rural areas and do not have access to processed foods that can be fortified with essential micronutrients. The idea of increasing essential micronutrients in the staple crops that these populations eat through conventional breeding has been translated into action over the past two decades. Much higher levels (usually to assure $50 \%$ of recommended daily intake) of vitamin $\mathrm{A}$, iron and zinc have been bred into staple foods eaten by poor rural populations in Africa and Asia. For these rural populations, the other major micronutrient deficiency is iodine. This is usually delivered via fortified salt, which is relatively widely available.

The main staples consumed by rural poor in Asia and Africa and the increased micronutrients targeted include: rice (zinc and iron), wheat (zinc and iron), maize (vitamin A), cassava (vitamin A), sweet potatoes (vitamin A), pearl millet (iron) and beans (iron). Over the past 10 years, the HarvestPlus program has increased micronutrient levels in the best yielding varieties in conjunction with national authorities or seed companies. They have done studies to establish the bioavailability and nutritional efficacy of these crops and have done initial ex-ante studies of acceptability and feasibility prior to scaling up efforts. Scaling up activities for high vitamin A sweet potato began in 2007 and will commence for other micronutrient enhanced crops from 2013. Focus from 2014 onward will be to mainstream higher micronutrients into breeding programs and accelerate wide-scale delivery of biofortified varieties to smallholder farmers in rural Africa and Asia with a target of reaching 100 million households by 2020. In addition to increasing adoption, research in Latin America with Embrapa is also looking at the contributions of biofortified crops in the overall food basket and the nutrient and micronutrient intakes of those diets.

Diversifying crop production and sustainable diets within sustainable production systems

International agricultural research and development has most focused on and has been most successful in improving the productivity of food staples, particularly rice, wheat and maize. Over the past 50 years, this has been associated with a general improvement in global food security, particularly in Asia, and a real decline in the prices of food staples relative to other foods. Presentations by Diversity for Development, FAO and Bioversity, argued for a new emphasis on diversifying plant 
and animal food production and marketing systems and a greater emphasis on management of agro-ecosystems for more diverse diets and for more sustainable and resilient production. Some agro-ecosystems of particular interest include agriculture, forests and aquatic environments. In terms of nutritionsensitivity, the focus is on applying a nutrition lens across the production of diverse foods from discovery to support and delivery. This includes promoting genetic resource conservation and production and marketing of more diverse crops, vegetables and fruits, including indigenous and underutilized varieties. Analysis also focuses on nutritional benefits in managing the dietary transition and the rapid rise in obesity and noncommunicable diseases in low and middle income countries. A new publication on the sustainable diets approach can be found at http://www.fao.org/docrep/016/i3004e/i3004e00.htm.

\section{Capacity development, extension support and partnerships to implement and enable nutrition-sensitive agriculture}

Invariably, serious discussions about improving household nutrition security emphasize the critical roles of gender empowerment, engagement of communities, methods to extend knowledge and information and the multiple needs for building capacity for implementation and enabling. In many of the session presentations at GCARD2 these requirements were sometimes explicitly raised but usually implicitly included. In this section, we highlight explicit points and draw out the implicit themes.

Gender empowerment and nutrition security are intimately linked. Both ACF and HKI pay special attention to gender empowerment and intra-household allocation in their integrated agriculture-nutrition programs targeted at the household level. There is a growing body of information on strategies and practices for gender empowerment to address women's time constraints, income and assets and decision making role relative to men (Gillespie et al. 2012; CGIAR Research Program (CRP) on Agriculture for Nutrition and Health (A4NH) 2012). The FAO State of Food and Agriculture report (FAO 2011) brings together many issues around agriculture and gender such as within household empowerment and engagement of both men and women. Both analyses (Gillespie et al. 2012) and documented case studies (FAO 2011) demonstrate that gender empowerment is necessary to achieve household nutrition security. More research and development experience is needed to determine how best to implement approaches in different contexts.

In the implementation of the programs discussed, there were a number of different approaches for extending knowledge and information. Clearly, local context matters in the success of different approaches. Household nutrition security is complex and in low-income countries can be improved by contributions from agriculture, health and social development sectors. At present, cross-sectoral extension collaboration is handled in three ways: enhancing agricultural extension with nutrition and health messages, enhancing health extension with agriculture messages, or more integrated agriculture and health programs with extension messages formulated and delivered from both agriculture and health agents. We will focus more on extension through agriculture, supplemented with health. While integrated programs are conceptually attractive, there is much less experience with them.

Provision of knowledge and information on nutritionsensitive agricultural practices is more complex when program objectives evolve from simple household production and consumption of more nutritious foods to moving smallholder households into market-oriented systems that produce food for both sales to increase income and household consumption. Organizing knowledge, information, input supply, financial and output market services in smallholder systems is very challenging. Generally some kind of farmer- or communitybased institutional arrangement is required to enable more efficient provision of knowledge and services to smallholders. Beyond such market arrangements, it is important to consider new opportunities for empowerment and learning and innovations to knowledge and service provision. Increasingly, private sector players are becoming engaged in smallholder marketoriented systems. Also new technologies, particularly mobile phones offer innovative opportunities to accelerate knowledge and information flows.

The central objective in all capacity development models is to support adaptive learning among farmers and other key actors. The range of extension agents and methods has become more varied as traditional public sector extension systems have declined. Box 1 provides a summary of extension approaches in Uganda, highlighting the change agents who can help with learning and what approaches are used.

In the HKI food-based household nutrition programs described above, extension models integrate nutrition, agriculture and health sectors at the community and household levels. Community-based extension services are developed with local NGOs and government offices to reach underserved poor farmers. In addition to standard agricultural messages, nutrition and gender training and infant and young child feeding counseling is added on or integrated into the agricultureservice system. When women's empowerment is an issue, specific hubs to support women's marketing, post-harvest processing and income-generation skills are added. Farmers are linked to formal extension services, private sector suppliers and health services. Health service workers are provided with additional maternal and child care and nutrition training. Scaling up is often done through national agriculture research institutes and international "extension" organizations. Some general lessons from HKI's experiences are that participatory processes are crucial for joint learning between staff and 
Box 1 Experiences in agriculture extension applicable to nutritionsensitive agriculture in Uganda

a) Extension, learning and change agents

Trained Extensionists (Agriculture): Diploma or degree trained in agriculture and extension skills. These may work for government, NGOs, CSOs or private companies.

Community Health Workers: Diploma or certificate holders working in community or maternal and child health clinics.

School Teachers: Recruiting agriculturally trained teachers or providing additional training to existing teaches. Strategy is targeted at promoting agriculture among the young.

School Children: Some programs have begun to train and support school children to provide knowledge and innovations in their households.

Community agents: A number of NGOs train and support active farmers as extension facilitators. Sometimes the concept is also used in training trusted older women as health extensionists. Community agents are more likely to stay in their communities and can integrate new knowledge and innovations into local practice.

Experts/Consultants: organizations also get experts who train extension agents, farmers and other value chain actors in skills such as business planning and financial management. This may or may not be linked to private sector supply chains. They may also support development of innovation knowledge management and communication systems using radio, print media, internet and mobile phones.

b) Extension and learning approaches

Group facilitation: This is the most common capacity building system in Uganda. There are variants of the group formation process. Most groups are facilitated by an NGO or government extensionist.

Farmer field schools: Farmer field schools are found in many low and middle-income countries. These schools use group training and experiential learning to help farmers learn new techniques, solve problems and make decisions. (Davis et al. 2010)

\section{Program learning model}

This approach is used in Uganda for providing new knowledge and skills in a program to extensionists and farmer trainers.

\section{Participatory technology development}

This is the main method used in Uganda for introducing and adapting new technologies. It is often used in farmer field schools and is a useful process for enhancing utility and adoption of new technologies.

\section{Information access model}

New methods for virtual learning and knowledge and information access through mobile phones (SMS messages), radio and other media.

farmers and that care must be taken in combining agriculture, food and nutrition-health interventions as their rates of change and diffusion differ. As with initial experience across all these new methods of extension and knowledge management, more formal methods to assess programmatic and economic efficiency and effectiveness are required.

There is much to be learned about implementing enabling agriculture strategies for household nutrition. Traditionally, nutrition-specific interventions have been developed and communicated as standardized public health campaigns. In general, such campaigns are easily managed and monitored and can be highly effective and efficient. As more general development investments are adjusted to become more nutrition-sensitive, complexity increases. These efforts require cross-sectoral partnerships and, because they rely on indirect support pathways, need enabling of policy and investment. At present, there is very limited experience in crosssectoral policy process and raising the political commitment needed for nutrition-sensitive approaches. An obvious area for cooperation between agriculture and health is in interventions targeted at pregnant women and young children. This is a difficult target population for agriculture to reach alone and is better served by community health and maternal and child health programs and systems.

One interesting initial experience in trying to understand the cross-sectoral enabling environment for nutrition-sensitive development interventions is the South Asia Food and Nutrition Security Initiative (SAFANSI), coordinated by the World Bank. This initiative plans to overcome the relative lack of progress in improving under-nutrition compared to economic and agricultural growth - the so-called agriculture-nutrition disconnect. Initial analyses pointed to an action rather than an evidence deficit and highlighted three important factors. The first observation was that political processes for supporting nutrition were misaligned and not coordinated. One factor linked to this was that systematic learning and analysis was not being applied, leading to a lack of strategic decision-making and investments. This linked to the third observation, that resources were made available for improving nutrition but they were not well applied. This initial diagnosis led to a three-part action planenhancing analysis, political advocacy and building capacity of institutions, that is currently being implemented.

Transform Nutrition (www.transformnutrition.org) is another platform looking at cross-sectoral policy and enabling processes and how these interact and enable nutrition-sensitive actions across agriculture, social protection and gender empowerment. Cross-sectoral coordination between agriculture, health and social protection sectors is not common. While there is considerable logic in coordination across these sectors, there is not much experience in or evidence for doing so. This is an important area for new learning in order to decide how much joint effort is required or when more aligned efforts will be sufficient.

\section{Research needs, opportunities and challenges}

A good place to start in discussing research needs was provided in a presentation of a recent study by Hawkes et al. (2012) on Current and Planned Research on Agriculture for Improved Nutrition: a mapping and gap analysis, commissioned by the United Kingdom's Department for International Development. In assessing current and planned research, 135 institutions were contacted. From this sample, 151 projects 
met the inclusion criteria of agriculture projects with explicit nutrition-sensitive outcomes. Of these, 100 provided detailed information and 51 only more general information. Most (133) projects were part of larger programs, particularly the CRP on A4NH (57 projects) and university programs and networks (40 projects).

In mapping projects and assessing gaps, the study's authors developed a conceptual framework (Fig. 3), which describes agriculture and food interventions and practices, nutrition outcomes and impacts on foods and diets and indirect or intervening factors that need to be considered. The conceptual framework recognizes links to the bio-physical, social and economic context. Further details of the mapping and gap analysis procedures can be found in the study report. In terms of findings, some key research gaps identified were:

- few assessments of the performance of overall agri-food chains;

- weak understanding of the indirect impacts of agriculture on nutrition, including through household income and more generally through agricultural and economic growth;

- direct and indirect effects of agriculture policy decisions on nutrition outcomes;

- understanding of agricultural and cross-sector policy processes and the influence of governance and political economy on policy formulation and program development and implementation;
- limited research methods for assessing agriculture effects on nutrition outcome and impacts;

- research on consumer choice and behavior (research is overwhelmingly supply rather than demand led);

- rural-urban linkages in food systems given rapid urbanization and that the greatest demand changes come from urban consumers;

- research on study design, analysis and metrics; and

- economic analysis of the cost-effectiveness of programs.

The study also made some interesting observations about who was doing research and who was not. One group not participating in the research projects assembled was the private sector. Very few of the research projects were led by developing country institutions, although many had them as partners. The study also noted that there was a future pipeline of research projects in nutrition-sensitive agriculture, which has been an important gap in the past.

In the presentations and discussions in the GCARD2 session, many of these gaps were expressed, either explicitly or implicitly. We would like to highlight a broader research challenge and opportunity that cuts across the discussions. In research for development the tension between how much research and evidence is needed and how much we can implement already is constant. This tradeoff might be described at one extreme as "we already know enough and we just need to act" and there is no need for additional research to the other extreme of "funds are limited and we need evidence on greatest benefits/

Research chain for agriculture and nutrition

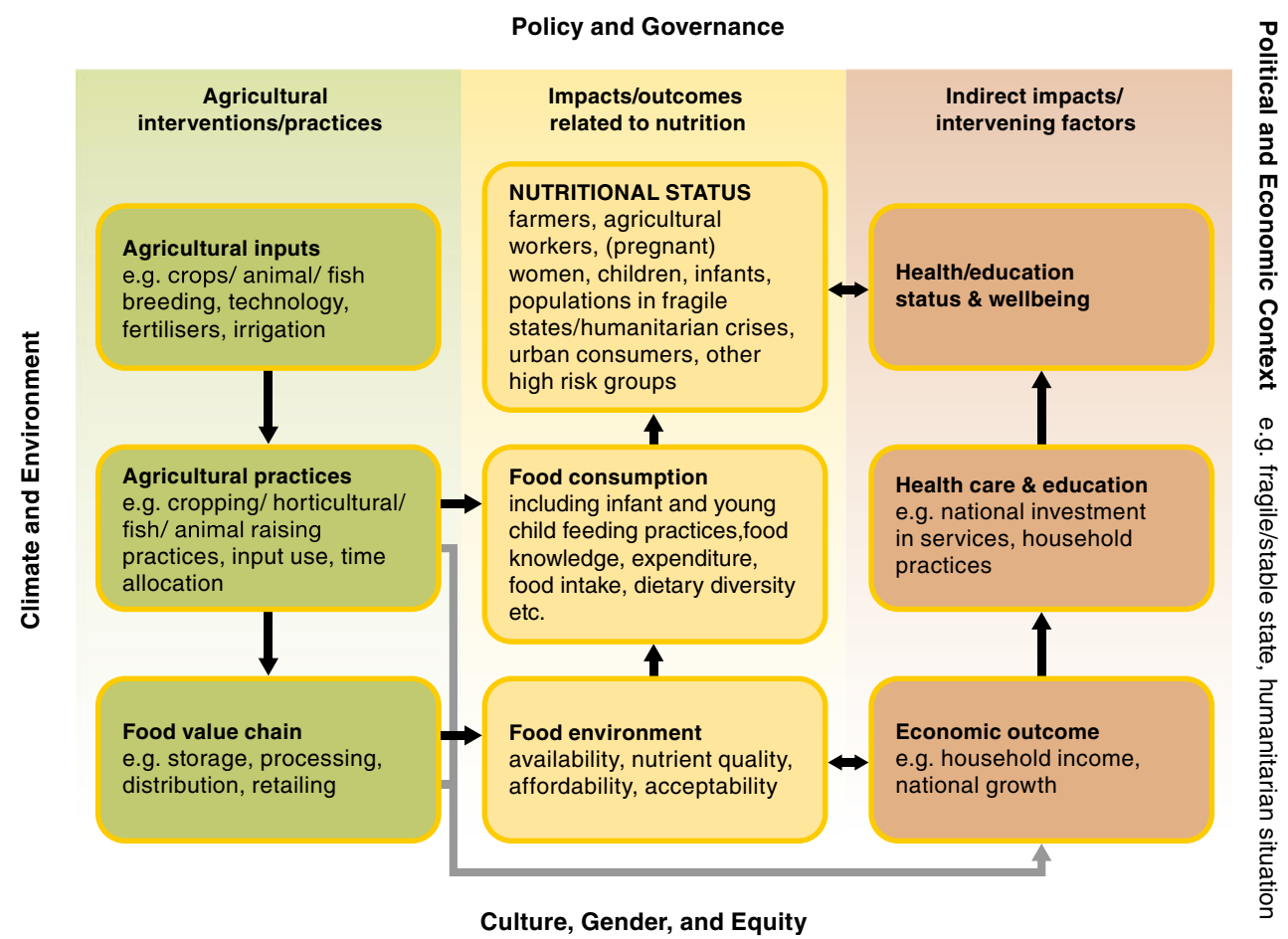

Fig. 3 Conceptual framework of a research chain for agriculture and nutrition (from Hawkes et al. 2012) 
effectiveness for money and some current interventions are at best unhelpful and at worst harmful" and research is needed.

In the discussions between development program implementers and researchers, there are pragmatic paths in the short-term. One approach is to build in process or operational research into development interventions and link this to outcome and impact evaluation. This will help to support development implementers in improving program implementation (what to do, how to combine and sequence inputs, and how to build capacity and deliver) and in assessing (either by themselves or with others) cost-effective approaches to implementation and learning. An obvious opportunity is in better understanding what we can learn from lighter project and program monitoring and evaluation and what topics need more fundamental and rigorous research. To date, the experience in nutrition-sensitive agriculture has been that research to evaluate nutritional outcomes from agricultural interventions has suffered from poor study design, lack of power and poor analysis (see for example Masset et al. 2011). Clearly, there is a large gap in current evaluation practice: increased investment in a portfolio of rigorous research is therefore needed. Development implementers, policy makers and investors need initial guidance on what interventions they may be confident about and which ones are less likely to work. Above all they need guidance on what interventions and policies might be making nutrition outcomes worse.

This challenge is much greater for nutrition-sensitive or indirect interventions as they are much more complex. Currently, relatively simple agricultural interventions such as household production of nutritious foods and biofortification are easiest to assess. However, experience, presented at GCARD2 and elsewhere, highlights that household food production does need to be linked to nutrition and health interventions and education for improving diet quality and nutritional outcomes. For more complex systems such as nutrition-sensitive agri-food value chains and beyond that to sustainable diets, the research challenges are much greater. A helpful starting place is to develop impact pathways and theories of change for different types of nutrition-sensitive agriculture interventions and policies. This is an active area of interest of the CGIAR, see for example a paper commissioned by the CGIAR Independent Science and Partnership Council by Webb (2013).

Particularly challenging are understanding more complex research areas such as changing overall agri-food systems through paradigms such as sustainable diets. The linkages between food security, livelihoods, nutrition and health are complex, global and rapidly evolving (Waage et al. 2010). Agri-food systems can be adjusted to enhance positive benefits such as improved nutrition, but the increasing intensification of agriculture to feed and nourish a growing and more affluent world population also comes with health risks such as emerging diseases and managing food safety. We have relatively weak knowledge of managing natural systems in terms of improving and valuing environmental and ecosystem services, and both short and longer-term risk assessment and climate change adaptation and mitigation to name a few. Likewise, low and middle income countries with the highest burden of stunting and agriculture-associated diseases are most dynamic. They are growing, getting richer and rapidly urbanizing. The aspirations and actions of poor people also change, as do their decisions about income, employment and spending. In these complex systems, initial attention and gradual improvements in impact pathways and theory of change can be helpful in supporting participatory discussions on goals, desirable outcomes and trade-offs and formulating research hypotheses and approaches.

\section{Summary}

This paper has built on the presentations and discussions from the household nutrition security session at the GCARD2 conference in 2012. From our diverse perspectives, we have synthesized information from the conference and added some additional perspectives in describing the current status and future prospects of nutrition-sensitive agricultural research and development.

There has been much progress in specific building blocks for nutrition-sensitive agriculture in the recent past. A richer experience of integrated agriculture and nutrition programs both by researchers and implementers is being obtained and definitions, research approaches and methods are and will be improved upon. Some other agricultural contributions, such as biofortified crops, have also made dramatic technical progress and are advancing thinking on scaling-out delivery. More systematic assessments of research gaps and improving thinking about impact pathways and theory of change will be important areas on which to build.

As for the next steps, any research and development progress needs to translate into improvement in nutritional outcomes and impacts for pregnant women and children and high-burden, undernourished populations. We see four major areas for action in this regard.

The first is to continue working on how to bring the different necessary but insufficient contributions to improved nutrition together to accelerate progress in reducing household nutrition insecurity. This includes agricultural interventions, the focus of this paper, as well as health services, water and sanitation and social protection for vulnerable groups. More coordinated thinking between different development sectors and between researchers, development implementers and development enablers will also be required.

A second step is to work on systems to accelerate learning. Much more work needs to be done in some key areas of intervention, particularly on supporting households in better nutrition decision making, improving the nutritional quality 
and food safety in agricultural value chains, and assessing the implications of policy and investment decisions. Smarter learning systems of appropriate cost and benefit will need to bring together monitoring and evaluation of operations and delivery as well as impact evaluation of agreed outcomes established through systematic and participatory processes.

A third and often forgotten step is to build capacity in order to adapt and innovate, particularly at community level and among professionals and decision makers in target communities and countries. Milestones assessing changes in knowledge and performance and testing of new approaches and how to learn more quickly and adapt are required. This is an essential and long-term step that needs to be accelerated and linked to current actions, expertise and capacities.

Finally, for improving nutritional outcomes, gender empowerment and empowerment of disadvantaged groups is critical. In gender empowerment, attention must be paid to the critical role of women in household decision making, nutrition and child care. The relative roles of men and women and involving men are essential to consider. Likewise, much of chronic undernutrition is related to the capacity of households. The demands on poor households relative to their capacity are enormous and assessing programs that support poor households to build their capacity are essential if progress on reducing stunting is to be sustained and accelerated.

Acknowledgments The authors thank the organizers of the GCARD2 household nutrition security session as well as the other discussants and participants. They provided much food for thought. The authors are responsible for additional conclusions and analysis and for any misinterpretations and other errors.

Open Access This article is distributed under the terms of the Creative Commons Attribution License which permits any use, distribution, and reproduction in any medium, provided the original author(s) and the source are credited.

\section{References}

Black, R., Allen, L., Bhutta, Z., Caulfield, L., De Onis, M., Ezzati, M., et al. (2008). Maternal and child undernutrition: global and regional exposures and health consequences. Lancet, 371, 40.

CGIAR research program on agriculture for nutrition and health (2012). Gender strategy (www.a4nh.cgiar.org).

Davis, K., Nkonya, E., Kato, E., Mekonnen, D. A., Odendo, M., Miiro, R., et al. (2010). Impact of farmer field schools on agricultural productivity and poverty in East Africa. Washington DC: IFPRI.

FAO (2011). State of food and agriculture-women in agriculture. (http://www.fao.org/docrep/013/i2050e/i2050e00.htm).

Gillespie, S., Harris, J., Kadiyala, S. (2012). The agriculture-nutrition disconnect in India. What do we know? Discussion Paper 01187. Washington DC, USA: International Food Policy Research Institute.

Grantham-McGregor, S. M., Walker, S. P., \& Chang, S. (2000). Nutritional deficiencies and later behavioural development. Proceedings of the Nutrition Society, 59, 47-54.
Gwatkin, D. R., Rutstein, S., Johnson, K., Suliman, E., Wagstaff, A., \& Amozou, A. (2007). Socio-economic difference in health, nutrition and population within developing countries: an overview. Washington DC: World Bank.

Hawkes, C., Turner, R., Waage, J. (2012). Current and Planned Research on Agriculture for Improved Nutrition: a mapping and gap analysis. Report commissioned by the United Kingdom's Department for International Development. http://r4d.dfid.gov.uk/pdf/outputs/misc susag/LCIRAH_mapping_and_gap_analysis_21Aug12.pdf.

Iannotti, L., Cunningham, K., \& Ruel, M. (2009). Diversifying into healthy diets: Homestead food production in Bangladesh. In D. J. Spielman \& R. Pandya-Lorch (Eds.), Millions Fed: Proven successes in agricultural development. Washington DC: International Food Policy Research Institute.

Lim, K., et al. (2012). A comparative risk assessment of burden of disease and injusry attributable to 67 risk factors and risk factor clusters in 21 regions, 1990-2010: a systematic analysis for the Global Burden of Disease Study 2010. Lancet, 380(9859), 2224-2260.

Maluccio, J. A., Hoddinott, J., Behrman, J. R., Martorell, R., Quisumbing, A., \& Stein, A. D. (2005). The impact of experimental nutritional interventions on education into adulthood in rural Guatemala. Washington, D.C: Food Consumption and Nutrition Division, IFPRI.

Masset, E., Haddad, L., Cornelius, A., \& Isaza-Castro, J. (2011). A systematic review of agricultural interventions that aim to improve nutritional status of children. London: EPPI-Centre, Social Science Research Unit, Institute of Education, University of London.

Matorell, R., Horta, B. L., Adair, L. S., Stein, A. D., Richter, L., Fall, C. H. D., et al. (2010). Weight gain in the first two years of life is an important predictor of schooling outcomes in pooled analyses from five birth cohorts from low- and middle- income countries. Journal of Nutrition, 140, 348-354.

Ruel, M., \& Hoddinott, J. (2008). Investing in early childhood nutrition. IFPRI Policy Brief 8. Washington DC: International Food Policy Research Institute.

Spielman, D. J., \& Pandya-Lorch, R. (Eds.). (2009). Millions fed: Proven successes in agricultural development. Washington DC: International Food Policy Research Institute.

Tanimichi-Hoberg, Y. 2012. Presentation at GCARD conference (http:// www.fao.org/docs/eims/upload/305562/GCARD2-Briefing\% 20Paper\%20\%20P1-2\%20World\%20Bank_DO_.pdf).

Unicef. (1990). Strategy for improved nutrition of children and women in developing countries. A UNICEF policy review. New York: UNICEF.

UNICEF-WHO-The World Bank. (2012). Joint child malnutrition estimates-levels and trends in the child malnutrition. (http://www.who. int/nutgrowthdb/jme unicef_who_wb.pdf).

Waage, J., Dangour, A. L., Hawkesworth, S., Johnston, D., Lock, K., Poole, N., et al. (2010). Understanding and improving the relationship between agriculture and health. London: Foresight Project on Global Food and Farming Futures.

Webb, P. (2013). Impact pathways for agricultural research to improved nutrition and health: a literature analysis and recommendation for research priorities. Report to the CGIAR Independent Science and Partnership Council.

Webb, P., \& Block, S. (2012) Support for agriculture during economic transformation: Impacts on poverty and undernutrition. PNAS, 109, 12309-12314. doi:10.1073/pnas.0913334108.

Wiggins, S., \& Keats, S. (2013). Smallholder agriculture's contribution to better nutrition. A report commissioned by the Hunger Alliance. London: Overseas Development Institute.

World Bank. (2013). Improving nutrition through multi-sectoral approaches. https://www.securenutritionplatform.org/Pages/Display Resources.aspx?RID=151 


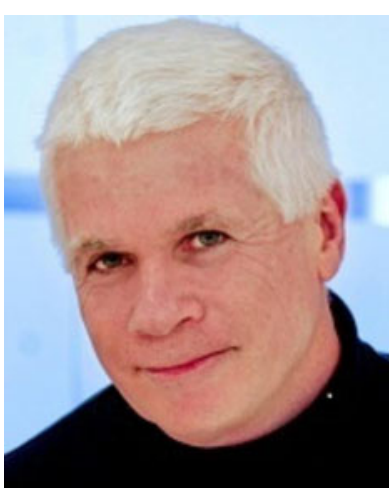

John McDermott is the Director of the new CGIAR research program on agriculture for nutrition and health, led by the International Food Policy Research Institute (IFPRI). He has lived and worked in Africa and Asia for 25 years conducting research on public health and agriculture, particularly in the areas of mixed crop-livestock smallholder agriculture and in zoonoses, emerging diseases and food safety. John has a strong background in quantitative methods, is the author or co-author of 200 peer-reviewed publications, book chapters and conference papers and has directly advised over 30 post-graduate students, including $20 \mathrm{PhD}$ graduates.

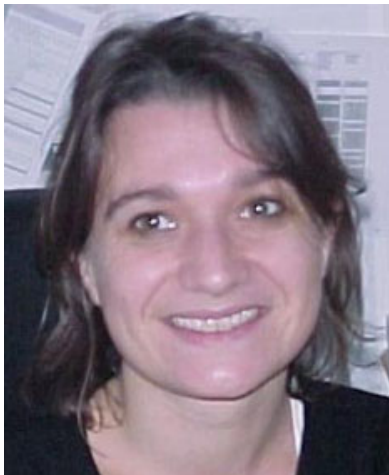

Myriam Ait Aissa has been the Head of the Research Department at Action Contre la Faim - ACF International since 2007. She is responsible for orienting, coordinating, supervising, promoting and providing technical support to ACF operational research projects, both in countries with ACF projects and globally. Previously, Myriam has worked as a research manager on food security issues in France, North Africa, South America and Canada. Myriam trained as an agronomist and holds a Master's Degree in Human nutrition and a Master's degree in food science from AgroParisTech (France).

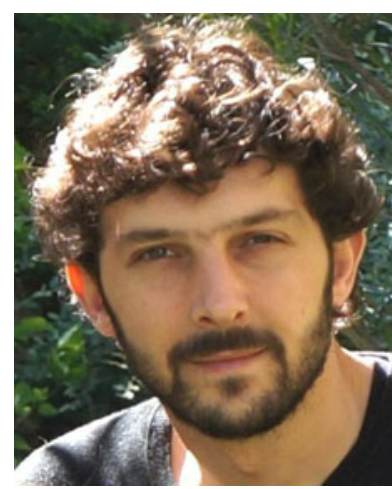

Julien Morel is the Food Assistance and Policy Senior Advisor with Action Contre la Faim ACF International. He is responsible for technical and policy development and advice and internal learning and capacity building. He is the policy and advocacy focal point for nutrition security, food assistance and social transfers. Prior to his current appointment, Julien was the Food Security \& Livelihoods Advisor for Action Contre la Faim, covering Afghanistan, Haiti and Zimbabwe. He has also had field postings in Cambodia, Indonesia, Sudan, Afghanistan and Sierra Leone. Julien holds a Master's Degree in humanitarian project management from Paris XII - Val de Marne University (France) and a Master's Degree in rural development and environment from the University of Bourgogne (France).

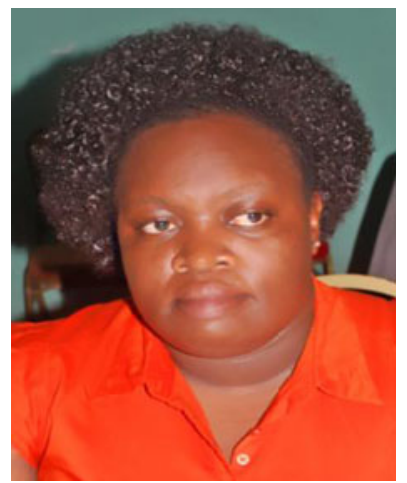

Nancy Rapando is the Program Director for agriculture and livelihoods with VEDCO Uganda. She has 9 years of experience in the development sector in Uganda and Kenya. VEDCO (Volunteer Efforts For Development Concerns) is an NGO working on improving the livelihoods of small holder farmers in Uganda through improved food and nutrition security, market access and farmer institutional development while handling advocacy, gender, climate change and HIV/AIDS as cross cutting issues. As Program Director, Nancy has led the development of agriculture and nutrition programs by ensuring that technology and knowledge transfer systems are developed to ensure that communities are able to integrate nutrition into agriculture. Nancy holds a Master's Degree in Agriculture and a Bachelor's Degree in Agricultural Education and Extension from Egerton University, Kenya. 